\title{
A hypomorphic R229Q Rag2 mouse mutant recapitulates human Omenn syndrome
}

\author{
Veronica Marrella, ${ }^{1}$ Pietro Luigi Poliani, ${ }^{2}$ Anna Casati, ${ }^{3}$ Francesca Rucci, ${ }^{1}$ Laura Frascoli, ${ }^{1}$ \\ Marie-Lise Gougeon, ${ }^{4}$ Brigitte Lemercier, ${ }^{4}$ Marita Bosticardo,, ${ }^{5}$ Maria Ravanini, ${ }^{2}$ \\ Manuela Battaglia, ${ }^{5}$ Maria Grazia Roncarolo, 5 Marina Cavazzana-Calvo, 6 Fabio Facchetti, ${ }^{2}$ \\ Luigi D. Notarangelo, 7,8 Paolo Vezzoni, ${ }^{1}$ Fabio Grassi, ${ }^{3}$ and Anna Villa1,5
}

\begin{abstract}
${ }^{1}$ Human Genome Department, Istituto di Tecnologie Biomediche, CNR, Segrate, Milan, Italy. 2Department of Pathology, University of Brescia, Brescia, Italy. ${ }^{3}$ Institute for Research in Biomedicine, Bellinzona, Switzerland. ${ }^{4}$ Antiviral Immunity, Biotherapy, and Vaccine Unit, INSERM 668, Infection and Epidemiology Department, Institut Pasteur, Paris, France. 5Università Vita-Salute San Raffaele Telethon Institute for Gene Therapy, Milan, Italy. ${ }^{6 I N S E R M ~ U 768, ~ U n i v e r s i t e ́ ~ R e n e ́ ~ D e s c a r t e s, ~ P a r i s, ~ F r a n c e . ~}{ }^{7}$ Department of Pediatrics, University of Brescia, Brescia, Italy. ${ }^{8}$ Division of Immunology, Children's Hospital, Harvard Medical School, Boston, Massachusetts, USA.
\end{abstract}

\begin{abstract}
Rag enzymes are the main players in $V(D) J$ recombination, the process responsible for rearrangement of TCR and Ig genes. Hypomorphic Rag mutations in humans, which maintain partial V(D)J activity, cause a peculiar SCID associated with autoimmune-like manifestations, Omenn syndrome (OS). Although a deficient ability to sustain thymopoiesis and to produce a diverse $T$ and $B$ cell repertoire explains the increased susceptibility to severe infections, the molecular and cellular mechanisms underlying the spectrum of clinical and immunological features of OS remain poorly defined. In order to better define the molecular and cellular pathophysiology of OS, we generated a knockin murine model carrying the Rag2 R229Q mutation previously described in several patients with OS and leaky forms of SCID. These Rag2 ${ }^{\mathrm{R} 229 \mathrm{Q} / \mathrm{R} 229 \mathrm{Q}}$ mice showed oligoclonal $\mathrm{T}$ cells, absence of circulating B cells, and peripheral eosinophilia. In addition, activated $T$ cells infiltrated gut and skin, causing diarrhea, alopecia, and, in some cases, severe erythrodermia. These findings were associated with reduced thymic expression of Aire and markedly reduced numbers of naturally occurring Tregs and NKT lymphocytes. In conclusion, $\operatorname{Rag} 2^{\mathrm{R} 229 \mathrm{Q} / \mathrm{R} 229 \mathrm{Q}}$ mice mimicked most symptoms of human OS; our findings support the notion that impaired immune tolerance and defective immune regulation are involved in the pathophysiology of OS.
\end{abstract}

\section{Introduction}

Omenn syndrome (OS) is a peculiar immunodeficiency in which a defect in immune response against pathogens coexists with signs of autoimmunity $(1,2)$. Clinically described for the first time in 1965 (3), OS has been characterized at the clinical level as a SCID with erythrodermia, hepatosplenomegaly, failure to thrive, susceptibility to infections, diarrhea, and a fatal outcome, unless treated with bone marrow transplantation (3-6). At the laboratory level, patients manifest eosinophilia and elevated $\operatorname{IgE}$ despite the absence of B cells, while T cell numbers are often normal or elevated. Although these T cells are oligoclonal, show a limited TCR repertoire, and express activation markers, they are not functional, thus justifying the combined nature of the immunodeficiency $(7,8)$. Mutations in either Rag1 or Rag2 are found in most, but not all, OS patients. Interestingly, these mutated proteins seem to maintain partial activity, as they are able to direct some recombination events that give rise to oligoclonal $\mathrm{T}$ cell populations, which could be responsible for peculiar manifestations of OS. Indeed, OS patients show an autoimmune phenotype that is not present in SCID patients carrying null Rag mutations (9). Although the presence of partial recombination activity is a prerequisite for OS due to Rag defects, it is likely that environmental factors such as exposure to specific pathogens could trig-

Nonstandard abbreviations used: AIRE, autoimmune regulator; CDR3, third complementarity-determining region; DN, double negative; DP, double positive; EGFP, enhanced GFP; nTreg, naturally occurring Treg; OS, Omenn syndrome; SP, single positive; UTR, untranslated region.

Conflict of interest: The authors have declared that no conflict of interest exists. Citation for this article: J. Clin. Invest. 117:1260-1269 (2007). doi:10.1172/JCI30928. ger the autoimmune response, since coexistence of SCID and OS in the same family has been described previously $(10,11)$. In particular, patients with typical OS-type Rag mutations who received bone marrow transplants very early did not manifest OS features, while their siblings who were diagnosed later did. More recently, other genes involved in OS have been described $(12,13)$, including a very rare Artemis mutation (14); this finding is also compatible with the same pathogenesis, since residual Artemis activity could allow a limited number of recombination events. Although the demonstration that the basic biochemical defect of OS lies in the process of recombination, this finding leaves several open questions. In particular, it is unclear whether selection of gene segments in V-to-J recombination is skewed in OS and whether $\mathrm{V}$ regions are selected for rearrangement based on their locations along the chromosome or on perfect matching of their recombination signal sequences. Furthermore, it is unknown whether secondary $\mathrm{V}(\mathrm{D}) \mathrm{J}$ rearrangements occur in OS. In addition, the mechanisms accounting for target tissue infiltration by activated lymphocytes are also largely unknown. Specifically, it is unclear whether defects in negative selection in the thymus or in generation and/or function of Tregs may play a role in the pathophysiology of peripheral tissue damage. Finally, the origin of elevated serum IgE remains to be defined, considering that IgE production requires normal $\mathrm{V}(\mathrm{D}) \mathrm{J}$ recombination and class switch, while few B cells are usually detected in OS patients.

Addressing these and other similar questions is challenging in humans, in which collection of samples is limited for ethical reasons. The availability of an animal model recapitulating the pathogenesis of OS would be important for understanding the cellular mechanism of this disease and might also provide useful insights 
A

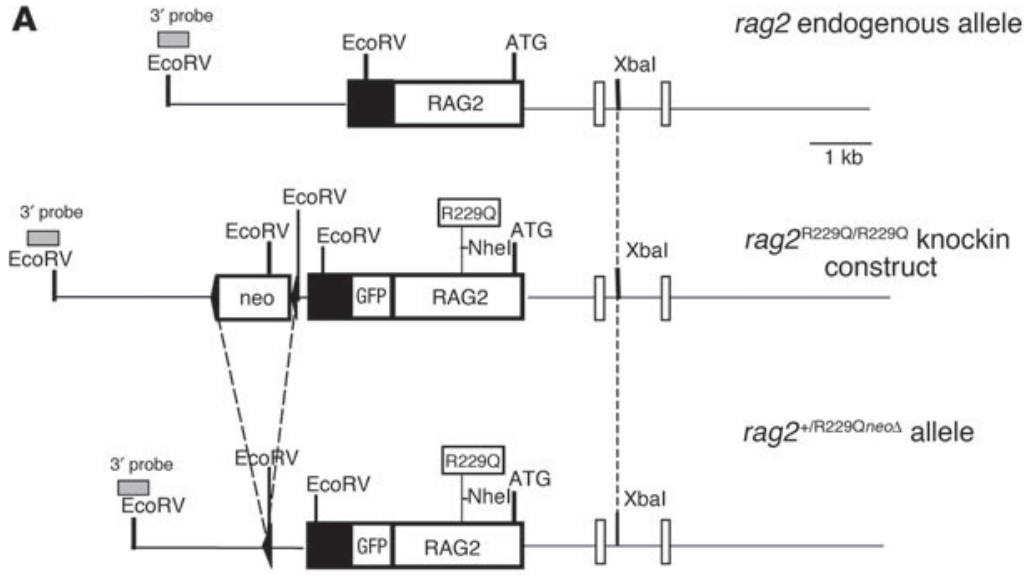

B

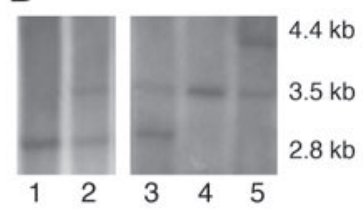

C

rag2 ${ }^{\text {R2290/R2290 }}$

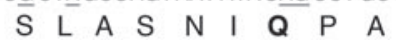

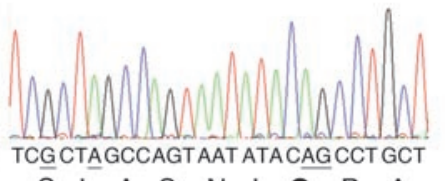

rag2 ${ }^{+1+}$ TCACTTGCCAGTAATATACGCCCTGCT

\section{Figure 1}

Generation of Rag2 ${ }^{\mathrm{R} 229 \mathrm{Q} / \mathrm{R} 229 \mathrm{Q}}$ ES cells and mice. (A) A targeting vector was designed to replace endogenous Rag2 with the gene carrying the R229Q substitution and an Nhel restriction site. GFP was fused in frame with the Rag2 neo cassette flanked by loxP sites (arrows), which was cloned downstream of the Rag2 UTR (black box). Gray boxes denote the 3' probe used for genomic screening. (B) Southern blot analysis using the $3^{\prime}$ probe on EcoRV-digested genomic DNAs. Lane 1, 129Sv wild-type ES cells; lane 2, Rag2+/R229Qneos recombinant ES cells; lane 3, heterozygous Rag2+/R229Qneos mouse after neo excision due to Cre cross; lane 4, 129Sv Rag2 ${ }^{+/+}$mouse; lane 5, Rag2+/R229Qneos mouse. (C) Chromatogram showing nucleotide substitutions, denoted by underline: the first 2 changes obtained the Nhel restriction site, the last 2 caused the $R$ to $Q$ amino acid change (bold). into the pathophysiology of autoimmunity in general. Therefore, through recombination in ES cells, we generated a knockin mouse bearing a mutation in the Rag 2 gene, which has previously been shown to be associated with OS in several patients $(10,11,15)$. This mouse showed a heritable phenotype very close to that of human OS, including development of oligoclonal and activated $T$ cells that infiltrate target tissues causing gut and skin abnormalities.

\section{Results}

Generation of the Rag2 $2^{R 229 Q} / R 229 Q$ model. A targeting construct bearing a Rag2/enhanced GFP (Rag2/EGFP) fused gene carrying the R229Q mutation and a novel NheI site was engineered to use for homologous recombination in ES cells (see Figure 1A and Methods). EGFP was introduced as gene reporter to follow the proper expression of Rag2 during $\mathrm{T}$ and $\mathrm{B}$ cell differentiation. This construct included about $3 \mathrm{~kb}$ of homology both upstream and downstream of the coding region containing the introduced mutation, and a neomycin resistance gene (PGK-neor) flanked by loxP sites was cloned downstream of the untranslated region (UTR) in the $3^{\prime}$ homology region.

Targeted replacement of Rag2 with the Rag2-R229Q/GFP vector was performed in 129Sv ES cells. PCR and Southern blot screening revealed that $1 \mathrm{ES}$ cell clone underwent the expected homologous recombination event (Figure 1B). Chimeric mice derived from ES cell clones were crossed with wild-type mice, and the heterozygous progeny was crossed with CMV-Cre-expressing mice in order to eliminate the neo cassette and thus obtain the founder knockin Rag2+/R229Qneos mice. We confirmed the excision of neo by Southern blot analysis (Figure 1B). These mice were crossed to produce the homozygous $\operatorname{Rag} 2^{\mathrm{R} 229 \mathrm{Q} / \mathrm{R} 229 \mathrm{Q}}$ mice used in this study, which were screened by direct sequencing (Figure 1C). Heterozygous mice did not show any immunological defects or growth impairment (data not shown).

Analysis of the progeny obtained after breeding heterozygous

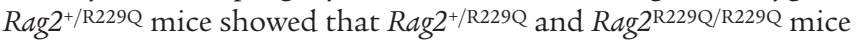

were viable and generated according to Mendelian inheritance. Homozygous Rag2 $2^{\mathrm{R} 229 \mathrm{Q} / \mathrm{R} 229 \mathrm{Q}}$ mice were fertile and were used to produce further generations, with an equal representation of male and female progeny.

Phenotypic analysis of Rag2 $2229 \mathrm{Q} / \mathrm{R} 229 \mathrm{Q}$ mice showed normal appearance at birth. However, at $8-10$ weeks of age, $60 \%$ of the homozygous mutant mice developed substantial dorsal and facial hair loss. In addition, after an initial period of normal growth, a minority (4\% of all $\operatorname{Rag} 2^{\mathrm{R} 229 \mathrm{Q} / \mathrm{R} 229 \mathrm{Q}}$ mice) started to develop severe alopecia, skin erythrodermia, and wasting syndrome due to colitis (Figure 2A).

Histological analysis of $\operatorname{Rag} 2^{\mathrm{R} 229 \mathrm{Q} / \mathrm{R} 229 \mathrm{Q}}$ mice revealed marked infiltration by $\mathrm{T}$ lymphocytes and eosinophils in the skin and gut (Figure 2, B and C) that contrasted with the overall lymphoid depletion observed in the thymus, lymph nodes, and spleen. Similar to what we observed in Rag2 $2^{-/-}$mice, immunostaining for cytokeratin 5, which detects medullary epithelium, revealed a diffuse network throughout thymic parenchyma with loss of corticomedullary differentiation in the thymi of Rag2 $2^{\mathrm{R} 229 \mathrm{Q} / \mathrm{R} 229 \mathrm{Q}}$ mice (Figure 2, D and E). Furthermore, unlike the thymic medullary region in $R a g 2^{+/+}$mice, the thymi in $R a g 2^{\mathrm{R} 229 \mathrm{Q} / \mathrm{R} 229 \mathrm{Q}}$ mice were defective in forming Hassall corpuscle-like clusters (data not shown) (16). Abnormal architecture was also observed in lymph nodes, which revealed severe $B$ cell depletion as well as a lack of $B$ follicles (Figure $2 \mathrm{~F}$ ) and were composed of a diffuse population of pale histiocytes and dendritic cells admixed with $\mathrm{T}$ cells and eosinophils (Figure $2 \mathrm{G}$ ). Moreover, scattered activated $\mathrm{CD}^{+}$and $\mathrm{CD} 30^{+}$immunoblasts were found in these areas (Figure 2G, right panels). Spleens from $\operatorname{Rag} 2^{\mathrm{R} 229 \mathrm{Q} / \mathrm{R} 229 \mathrm{Q}}$ mice showed similar morphological alterations, with severe depletion of the white pulp and particularly of B cells (data not shown). No Peyer patches were recognized in the gut. These pathological changes were consistently detected in all Rag2 $2^{\mathrm{R} 229 \mathrm{Q} / \mathrm{R} 229 \mathrm{Q}}$ mice at 6-8 weeks of age, regardless of the severity of clinical manifestations; however, the T cell infiltration and peripheral eosinophilia were more severe in mice that developed erythrodermia and wasting syndrome. 

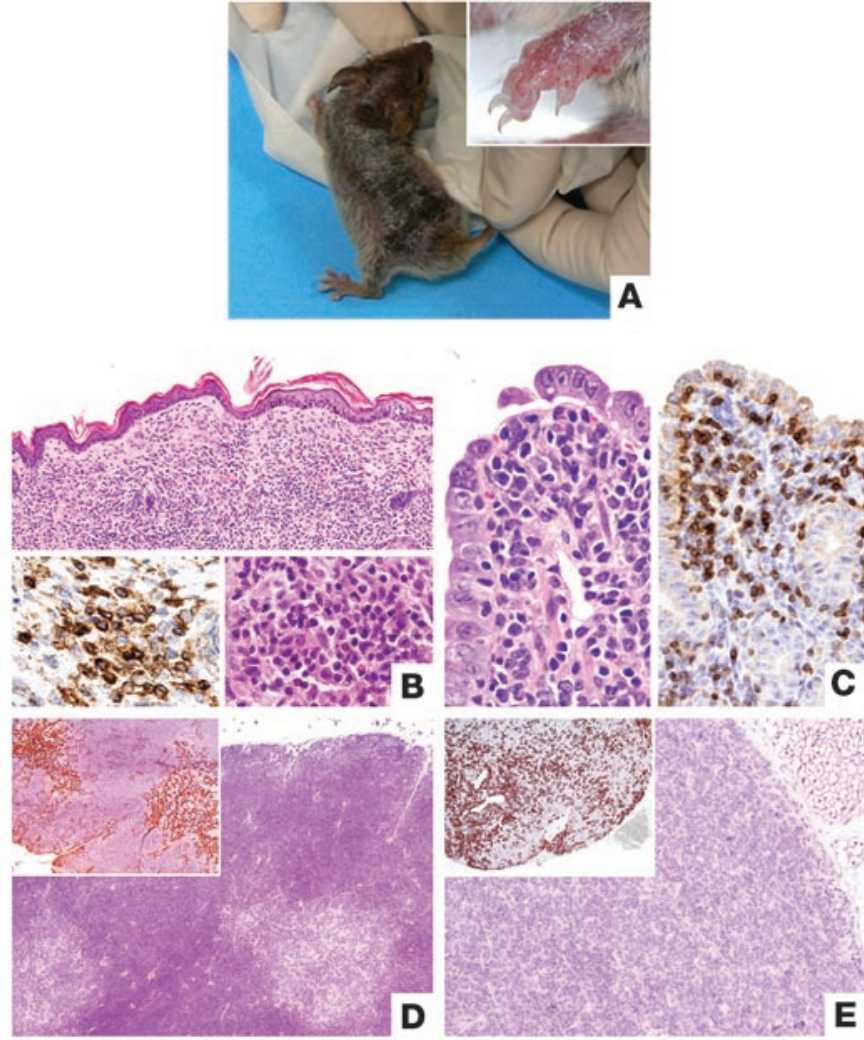

D
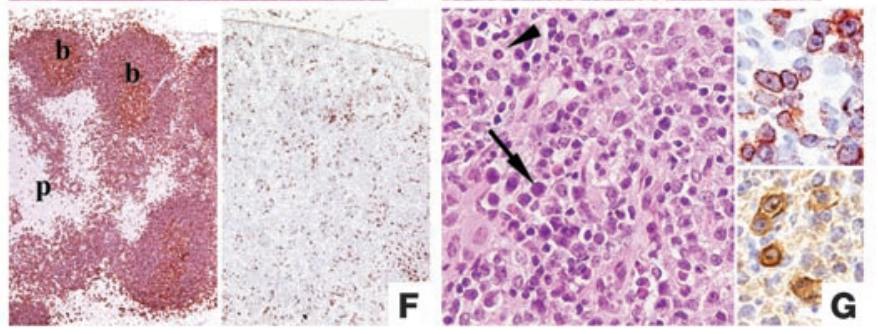

\section{Figure 2}

Histological analysis of Rag2 ${ }^{\mathrm{R} 229 \mathrm{Q} / \mathrm{R} 229 \mathrm{Q}}$ mice. (A) Phenotypic aspect of a 3-month-old Rag2R229Q/R229Q mouse, showing severe alopecia and skin erythrodermia. (B) Skin biopsy revealed marked dermal inflammation (top) composed of $\mathrm{CD}^{+}$lymphocytes (bottom left) and containing numerous eosinophils (bottom right). Original magnification, $\times 10$ (top); $\times 20$ (bottom). (C) Similarly, the gut showed dense inflammatory infiltration (left), mainly composed of $\mathrm{CD}^{+}$cells (right). Original magnification, $\times 20$. ( $\mathbf{D}$ and $\mathbf{E}$ ) Comparison between thymic tissue from age-matched 6-week-old Rag2+/+ and Rag2R229Q/R229Q mice: the normal corticomedullary differentiation observed in Rag2+/+ thymus (D), as highlighted by the anti-cytokeratin 5 immunostaining (D, inset), was absent in the Rag $2^{\mathrm{R} 229 \mathrm{Q} / \mathrm{R} 229 \mathrm{Q}}$ mouse (E and inset). Original magnification, $\times 4$ (D and E). (F) B220 immunostaining showed B follicles (b) and paracortical areas (p) in Rag2 ${ }^{+/+}$mice (left) in contrast to the abnormal architecture and severe depletion of B cells observed in Rag2 $2^{\mathrm{R} 229 \mathrm{Q} / \mathrm{R} 229 \mathrm{Q}}$ mice (right). Original magnification, $\times 4$. (G) Nodal parenchyma from the Rag2 $2^{\mathrm{R} 229 \mathrm{Q} / \mathrm{R} 229 \mathrm{Q}}$ (left) shows admixture of histiocytes, large activated lymphoid cells (arrow), and eosinophils (arrowhead); most lymphoid cells were CD3 $3^{+}$lymphocytes (top right) that expressed the activation antigen CD30 (bottom right). Original magnification, $\times 20$ (left); $\times 40$ (right).
$T$ cell differentiation in Rag2 $2229 Q / R 229 Q$ mice. Analysis of Rag2R229Q/GFP expression in thymocyte subsets revealed developmental regulation characteristic of $\operatorname{Rag} 2(17,18)$ (Supplemental Figure 1; supplemental material available online with this article; doi:10.1172/JCI30928DS1).

Cell recovery from Rag2 $2^{\mathrm{R} 229 \mathrm{Q} / \mathrm{R} 229 \mathrm{Q}}$ thymi was analogous to that of Rag2-/- thymi and markedly reduced compared with that of Rag2+/+ thymi (Supplemental Figure 2). Staining with CD4 and CD8 antibodies revealed a dramatic depletion of the $\mathrm{CD} 4^{+} \mathrm{CD} 8^{+}$double-positive (DP) compartment, with relative enrichment of the CD4-CD8double-negative (DN) subset, the predominant subset (Figure $3 \mathrm{~A}$ ).

Developmental progression of DN cells is characterized by an ordered sequence of phenotypes defined by CD44 and CD25 expression: $\mathrm{CD} 44^{+} \mathrm{CD} 25^{-}$(DN1) to $\mathrm{CD} 44^{+} \mathrm{CD} 25^{+}$(DN2), CD44CD25+ (DN3), and CD44-CD25- (DN4). The DN3 to DN4 transition is predominantly controlled by productive rearrangement of the TCR- $\beta$ locus and expression of the pre-TCR in the plasma membrane. Analysis of DN cells from Rag2 $2^{\mathrm{R} 229 \mathrm{Q} / \mathrm{R} 229 \mathrm{Q}}$ thymi with CD25 and CD44 antibodies revealed an almost complete arrest of thymocyte development at the DN3 stage, a hallmark of recombinase-deficient mice (Figure 3, A and B) (19). Nevertheless, a few DP cells were recovered and displayed progressive upregulation of TCR- $\alpha / \beta$ with concomitant expression of CD 69 , a feature of ongoing positive selection. $\mathrm{CD}^{+}$as well as $\mathrm{CD}^{+}$single-positive (SP) cells expressed high levels of TCR- $\alpha / \beta$, which suggests that minute amounts of thymocytes were positively selected and accumulated as SP cells (Figure 3A). Moreover, $\gamma \delta$ T cells were not detected (data not shown).

Next, we examined the T cell compartment in secondary lymphoid organs. The spleen and the mesenteric, inguinal, and cervical lymph nodes were severely reduced in size and dysmorphic, the absolute numbers of CD4 and CD8 lymphocytes and percentage of NKT cells were dramatically reduced (Supplemental Figure 2), and $\gamma \delta \mathrm{T}$ cells were absent. Flow cytometry analysis of lymph nodes showed a distribution of $\mathrm{CD}^{+}$and $\mathrm{CD}^{+} \mathrm{T}$ cells analogous to that of $\mathrm{Rag}^{+/+}$animals (Figure 4A); however, the vast majority $(\sim 80 \%)$ of cells in both subsets displayed an effector/memory-like $\mathrm{CD} 44^{+} \mathrm{CD} 62 \mathrm{~L}^{\text {low }}$ phenotype (Figure $\left.4 \mathrm{~A}\right)$. Similar observations were made in the spleen (data not shown).

To assess the functional activity of peripheral $\mathrm{T}$ cells in Rag2 ${ }^{\mathrm{R} 229 \mathrm{Q} / \mathrm{R} 229 \mathrm{Q}}$ mice, CD90 ${ }^{+}$cells were positively selected from total splenocytes and stimulated in vitro with increasing doses of anti-CD3 mAb. Proliferative responses were absent or markedly decreased in $R a g 2^{\mathrm{R} 229 \mathrm{Q} / \mathrm{R} 229 \mathrm{Q}}$ mice, and neither costimulation with 
A
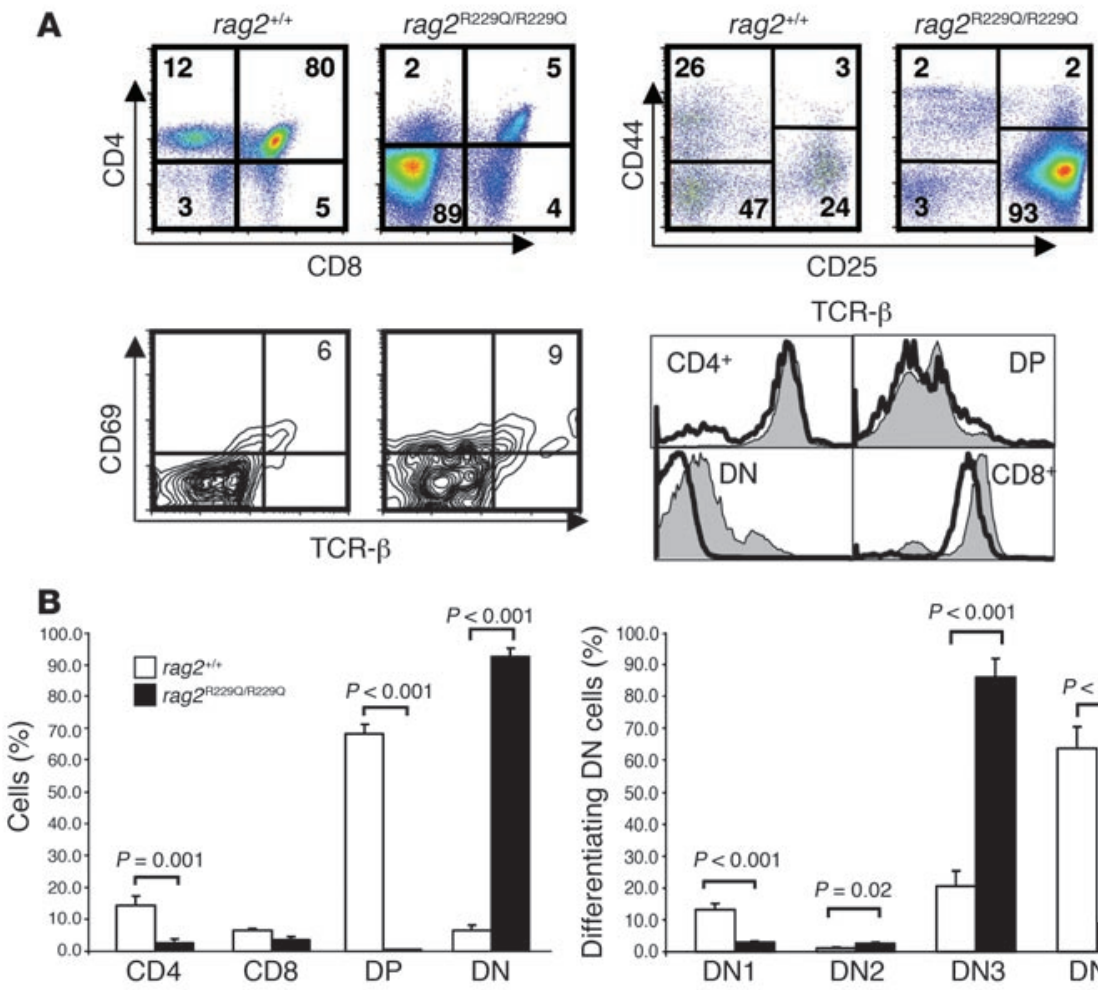

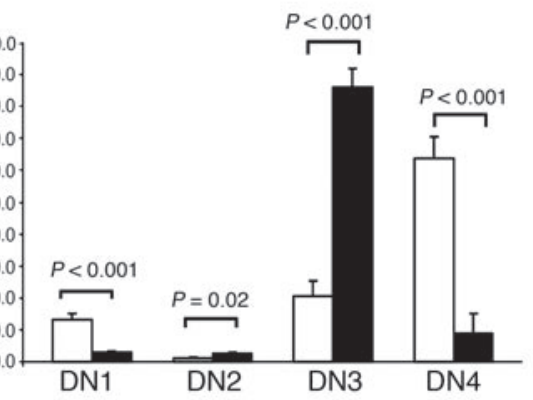

\section{Figure 3}

Impaired T cell development and aberrant peripheral T cell activation in Rag2 ${ }^{\mathrm{R} 229 \mathrm{Q} / \mathrm{R} 229 \mathrm{Q}}$ mice. (A) Top left: Fluorescence-activated cell sorting analysis of thymocytes from the indicated mice stained with CD4 and CD8 antibodies. Top right: CD4-CD8- cells were gated and analyzed for CD44 and CD25 expression. Bottom left: TCR- $\beta$ and CD69 expression in electronically gated $\mathrm{CD}^{+}{ }^{+} 8^{+}$ cells. The percentage of TCR- $\beta^{\text {bright }}$ CD69+ cells is indicated. Bottom right: Overlay of TCR- $\beta$ surface expression in the indicated thymocyte subsets (gray histograms,

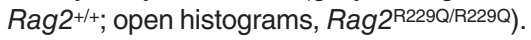
(B) Left: Percentage of cells during different $T$ cell differentiation stages in the thymus. Right: Percentage of differentiating DN cells. Results are the mean and SD of 5 Rag2 $2^{+/+}$ and 10 Rag2 ${ }^{\mathrm{R} 229 \mathrm{Q} / \mathrm{R} 229 \mathrm{Q}}$ mice. $P$ values were determined by unpaired Student's $t$ test.
CD28 (data not shown) or addition of IL-2 to the medium rescued $\mathrm{T}$ cell proliferation (Figure 4B). However, $\mathrm{T}$ cells stimulated with phorbol 12-myristate 13-acetate/iomomycin (PMA/iomomycin) showed increased intracellular production of IL-2, IFN- $\gamma$, and TNF- $\alpha$ in both CD4 and CD8 subsets (Supplemental Figure 3).

We analyzed $\mathrm{T}$ cell repertoire by investigating TCRV $\beta$ use among thymocytes and splenocytes obtained from 2 and 4 Rag2 $2^{\mathrm{R} 229 \mathrm{Q} / \mathrm{R} 229 \mathrm{Q}}$ mice, respectively, and the results were compared with those in Rag $2^{+/+}$mice. Figure 5 A shows that in $R a g 2^{\text {R2229Q/R229Q }}$ mice, use of some TCRV $\beta$ family members increased in frequency within total $T$ cells compared with that of Rag2 $2^{+/+}$mice, both in the thymus and in the spleen. Interestingly, while use of some TCRV $\beta$ family members, such as TCRV $\beta 3$, expanded both in the spleen and in the thymus, other members showed a different distribution in the 2 organs. The immunoscope profiles in Figure 5B demonstrate the diversity of the TCR by showing the distribution of TCR third complementarity-determining region (CDR3) length for each TCRV $\beta$-TCRC $\beta$ rearrangement. While the $R a g 2^{+/+}$mice showed a typical polyclonal distribution of CDR3 length, Rag2 $2^{\mathrm{R} 229 \mathrm{Q} / \mathrm{R} 229 \mathrm{Q}}$ mice presented oligoclonal patterns for most of the TCRV $\beta$ family members.

$B$ cell differentiation in Rag $2^{R 229 Q} / R 229 Q$ mice. Most patients with OS show absence or severely reduced numbers of circulating B cells and profound hypogammaglobulinemia in spite of high levels of IgE. In Rag $2^{\mathrm{R} 229 \mathrm{Q} / \mathrm{R} 229 \mathrm{Q}}$ mice, the number of $\mathrm{B} 220^{+}$cells was severely reduced in both bone marrow and spleen (Figure 6, A and B), suggesting that $\mathrm{B}$ cell development was impaired. In the bone marrow, productive rearrangement of the IgM heavy chain locus and expression of the membrane-bound pre-B cell receptor determines the developmental transition of $\mathrm{B}$ cell progenitors from the pro- $\mathrm{B}$ cell stage to the pre-B cell stage. We analyzed pro-B cell to pre-B cell transition by staining bone marrow cells with B220 and CD2 antibodies. As shown in Figure 6A, we observed a complete absence of $\mathrm{B} 220^{\text {low }} \mathrm{CD} 2^{+}$pre- $\mathrm{B}$ cells and $\mathrm{B} 220^{\text {high }} \mathrm{CD} 2^{+}$cells that comprised immature and mature recirculating $B$ cells, as was observed in Rag2 $2^{-/}$mice (20). Transitional B cells migrate to the spleen through the bloodstream and start to express membrane-bound IgD. IgM and $\operatorname{IgD}$ staining can distinguish transitional and mature recirculating B cells. In the bone marrow of Rag2 $2^{\mathrm{R} 229 \mathrm{Q} / \mathrm{R} 229 \mathrm{Q}}$ mice, both these cell subsets were undetectable (Figure 6A). In the spleens of Rag $2^{\mathrm{R} 229 \mathrm{Q} / \mathrm{R} 229 \mathrm{Q}}$ mice, few mature follicular $\operatorname{IgM}^{+} \mathrm{IgD}^{+} \mathrm{B}$ cells were detected, and transitional $\mathrm{B}$ cells were undetectable. Further staining of splenocytes for the complement receptor CD21 and the lowaffinity receptor for $\mathrm{IgE}, \mathrm{CD} 23$, revealed few $\mathrm{CD} 21^{+} \mathrm{CD} 23^{+}$mature follicular B cells and a lack of CD $21^{+} \mathrm{CD} 23^{-}$marginal zone B cells (21), showing that B cell development was severely compromised in $\operatorname{Rag}^{\mathrm{R} 229 \mathrm{Q} / \mathrm{R} 229 \mathrm{Q}}$ mice (Figure 6B).

Along with the severe defect in B cell differentiation, Rag2 $2229 \mathrm{Q} / \mathrm{R} 229 \mathrm{Q}$ mice showed hypogammaglobulinemia, with reduced levels of all IgG subclasses as well as of IgA and IgM. Although mean IgE serum levels were comparable to those of wild-type mice, some Rag $2^{\mathrm{R} 229 \mathrm{Q} / \mathrm{R} 229 \mathrm{Q}}$ mice had markedly increased $\operatorname{IgE}$ (Figure 7), which correlated with more pronounced phenotypic manifestations. Despite the presence of low but detectable Ig levels, Rag2R229Q/R229Q mice challenged with OVA were unable to produce OVA-specific antibodies (data not shown).

Central and peripheral tolerance in Rag $2^{R 229 Q / R 229 Q}$ mice. The appropriate development of the thymic epithelial component is particularly relevant for $\mathrm{T}$ cell homeostasis because medullary epithelium expresses tissue-specific self antigens under the control of the transcription factor autoimmune regulator (AIRE). Rag2 2229Q/R229Q mice displayed atrophic thymi, which were macroscopically indistinguishable from those of $\mathrm{Rag}^{-1-}$ mice, and did not reveal a medullary compartment in histochemical study. Analysis of Aire expression in $\operatorname{Rag} 2^{\mathrm{R} 229 \mathrm{Q} / \mathrm{R} 229 \mathrm{Q}}$ thymi revealed low levels of Aire mRNA, as 
A
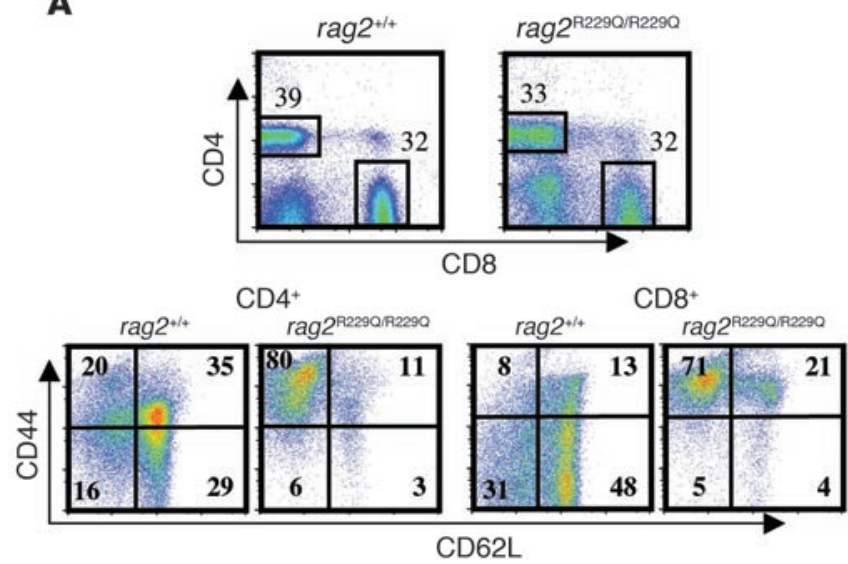

Figure 4

Peripheral T cells and T cell proliferation. (A) Top: Fluorescence-activated cell sorting analysis of lymph node cells stained with CD4 and CD8 antibodies. Bottom: $\mathrm{CD} 4^{+}$and $\mathrm{CD} 8^{+}$cells from the indicated mice were analyzed for CD44 and CD62L distribution. (B) Proliferation of Rag2 ${ }^{+/+}$and Rag2 $2^{\mathrm{R} 229 \mathrm{Q} / \mathrm{R} 229 \mathrm{Q}} \mathrm{CD} 90^{+}$cells isolated from splenocytes, plated at $2 \times 10^{5}$ cells per well, and stimulated as indicated. Proliferation was assessed by ${ }^{3} \mathrm{H}$-thymidine incorporation in triplicate wells. Plotted values are $\mathrm{cpm}$ for each individual mouse. Bars represent the median for each group. observed in Rag $2-/-$ mice, which are devoid of the medullary component of the organ (Figure 8A). In keeping with a possible defect in central tolerance related to reduced Aire expression, abnormal and severe lymphocyte infiltration in lungs and livers was observed in $\operatorname{Rag}^{2}{ }^{\mathrm{R} 29 \mathrm{Q} / \mathrm{R} 229 \mathrm{Q}}$ mice (Figure 8, B-E). Finally, we evaluated the
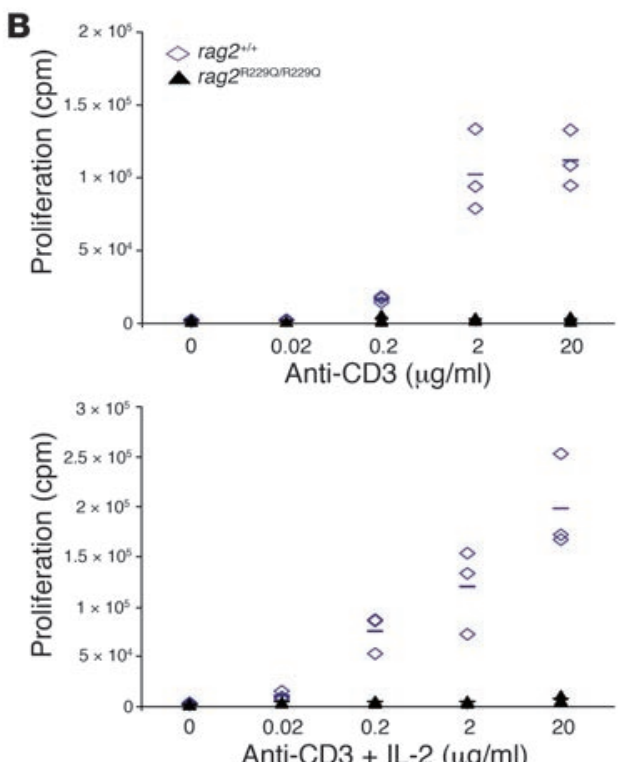

presence of naturally occurring Tregs (nTregs; defined here as $\mathrm{CD} 25^{\text {high }} \mathrm{Foxp}^{+}$) in our murine model. This subset has been shown to be crucial to prevent autoimmune manifestations (22). In order to determine whether $n$ Tregs could be reduced in $\operatorname{Rag}_{2} \mathrm{R} 229 \mathrm{Q} / \mathrm{R} 229 \mathrm{Q}$ mice, Foxp3 expression was analyzed in thymus, spleen, and
A

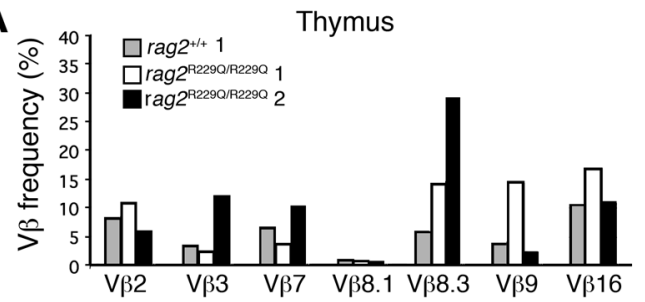

B

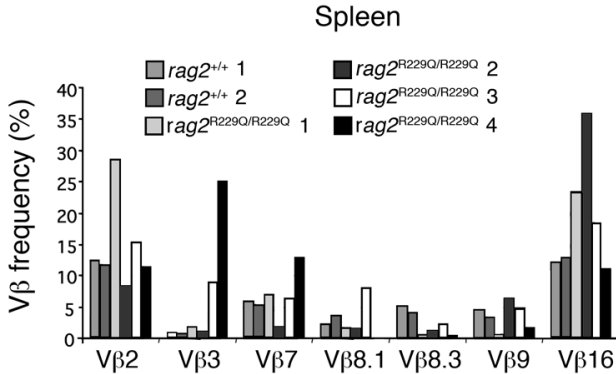

Figure 5

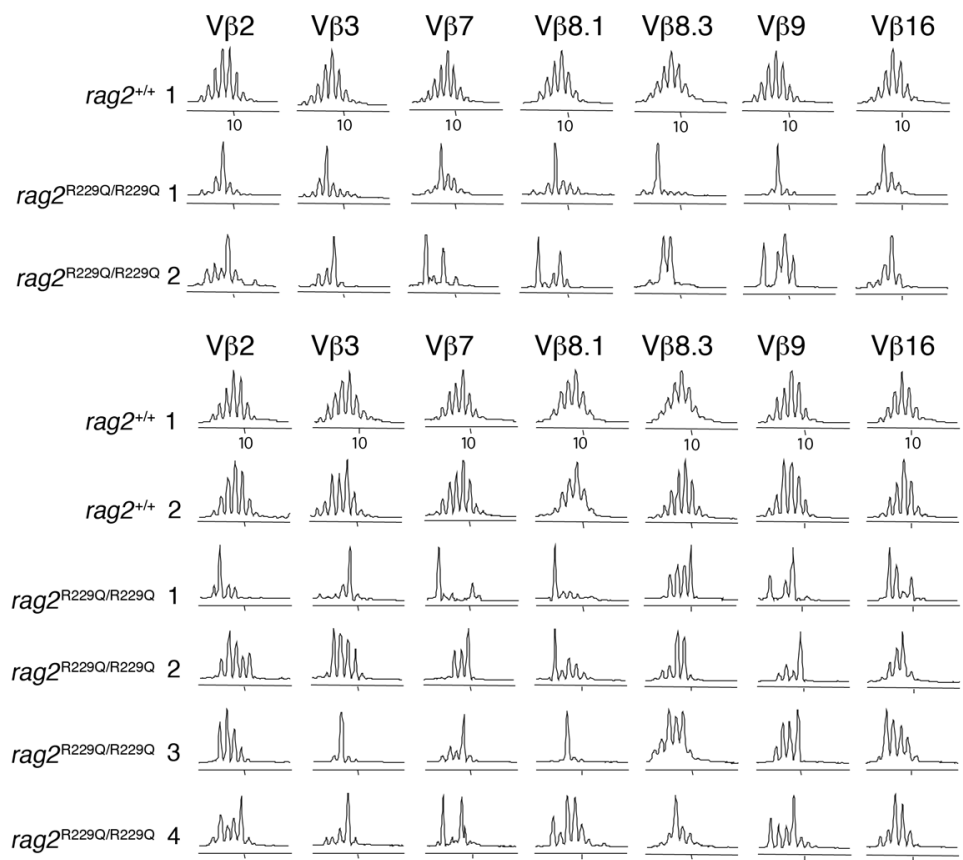

Immunoscope analysis of TCR repertoire. (A) Quantitative TCRV $\beta$ repertoire determined by real-time PCR analysis on T cells from the 2 thymi

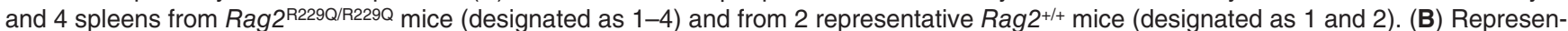
tative immunoscope profiles of TCRV $\beta$ analysis in the thymi and spleens of the mice as in A. The $x$ axes represent CDR3 length, and $y$ axes represent arbitrary fluorescence intensity of the runoff products. 

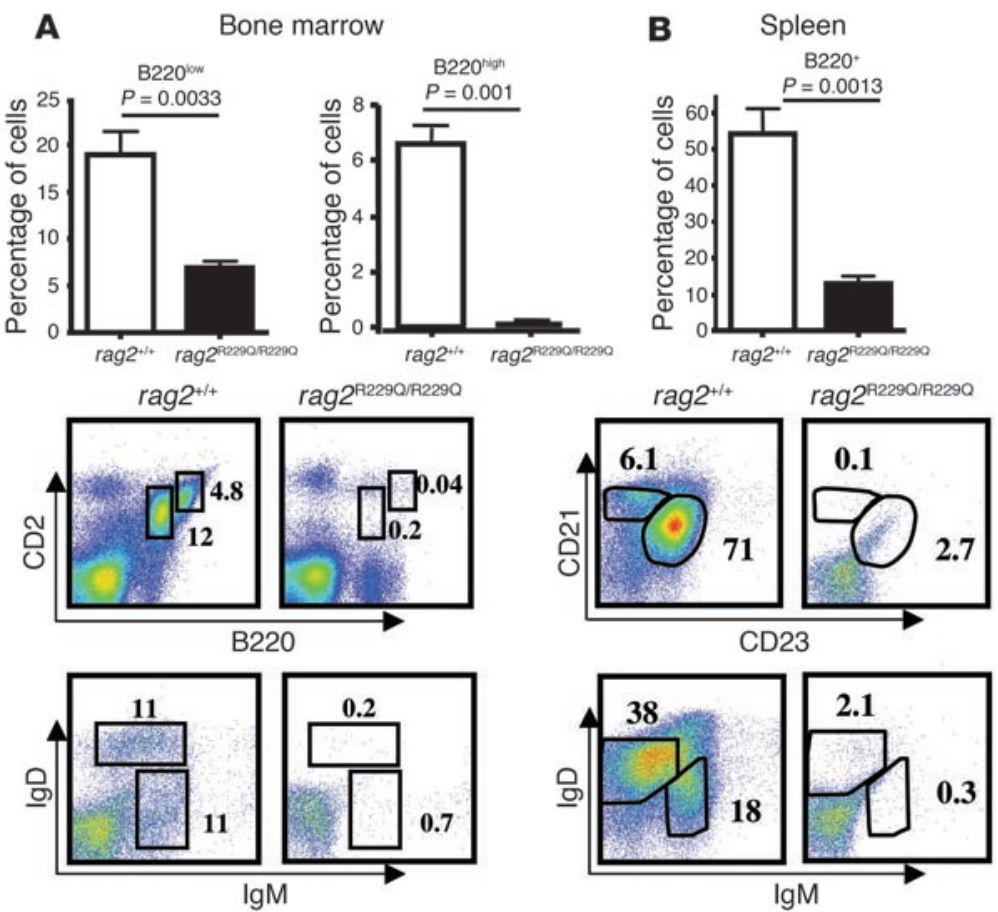

Figure 6

Impaired B cell development in Rag2R229Q/R229Q mice. (A) Top: Relative representation and SD of B220low and B220high cells in the bone marrow of the indicated mice $(n=6)$. Bottom: Dot-plot analysis of bone marrow cells from the indicated mice labeled with B220 and CD2 antibodies and IgD and IgM expression of electronically gated $\mathrm{B} 220^{+}$bone marrow cells. (B) Top: Relative representation and SD of $\mathrm{B}_{220^{+}}$cells in the spleens of the indicated mice $(n=6)$. Bottom: Dot-plot analysis of B220+ splenocytes labeled with CD21 and CD23 antibodies or $\operatorname{lgD}$ and IgM antibodies. $P$ values were determined by unpaired Student's $t$ test. Numbers indicate the percentage of cells in the indicated gates. lymph nodes. The number of nTregs in all tissues examined was significantly decreased in $R a g 2^{\mathrm{R} 229 \mathrm{Q} / \mathrm{R} 229 \mathrm{Q}}$ mice compared with Rag2 ${ }^{+/+}$mice (Figure 9).

\section{Discussion}

Hypomorphic mutations in Rag1 and Rag2 genes in humans have been associated with a spectrum of clinical and immunological manifestations that range from typical and severe $\mathrm{T}^{-} \mathrm{B}^{-}$SCID to leaky SCID (with residual production of $\mathrm{T}$ cells and occasionally B cells) to OS, a disorder characterized by the presence of autologous, activated T cells that infiltrate target organs (3). The reasons underlying this variable phenotype are unclear. Along with the primary genetic defect, both genetic background and environmental factors have been postulated to play a role in the pathophysiology of the disease $(23,24)$. In addition, defective thymopoiesis has been shown to impair Aire expression in the thymic medulla, thus disturbing negative selection of autoreactive T cells that may escape to the periphery and damage target organs (25). In agreement with these observations, a variety of genetic defects that affect early $\mathrm{T}$ cell development have been recently shown to cause OS in humans (12-14). In order to develop a model that recapitulates OS and could therefore be used to better dissect the mechanisms behind the various phenotypic manifestations of the disease, we have developed a homozygous Rag2 knockin mouse carrying the R229Q mutation. We chose to investigate the effects of this mutation, as it was originally described in a patient with leaky SCID (15), and we and others subsequently found this amino acid change in several patients with OS and in infants with leaky SCID $(10,11)$. In this regard, the R229Q mutation offers a unique setting in which to evaluate the contributory roles of genetic background and environmental factors in determining the phenotype. Biochemical investigation of this mutant form of Rag2 has previously been shown to reduce $\mathrm{V}(\mathrm{D}) \mathrm{J}$ recombination activity by over 150 -fold $(10,15)$.
We found that introduction of the Rag2 R229Q mutation did not affect viability and fertility in mice, but severely impaired $\mathrm{T}$ and $\mathrm{B}$ cell development and recapitulated most of the leaky features of OS. In particular, thymocyte development was predominantly arrested at the DN3 stage, during which expression of RAG is required to proceed along the differentiation pathway.

The few SP thymocytes generated in Rag $2^{\mathrm{R} 229 \mathrm{Q} / \mathrm{R} 229 \mathrm{Q}}$ mice expressed TCR- $\alpha / \beta$ at the cell surface and were exported to the periphery, where they infiltrated target organs. Interestingly, the pattern of $\mathrm{T}$ cell infiltration observed in $\operatorname{Rag}^{\mathrm{R} 229 \mathrm{Q} / \mathrm{R} 229 \mathrm{Q}}$ mice mimicked that observed in patients with OS, with preferential localization in the skin and in the gut. Furthermore, the infiltrating $\mathrm{T}$ lymphocytes express activation markers and are oligoclonal, suggesting selective peripheral expansion (8). Competition within an appropriate number of clonal specificities upon microbial infection could ensure self tolerance; thus the reduced diversity of the $\mathrm{T}$ cell repertoire in Rag2 $2^{\mathrm{R} 229 \mathrm{Q} / \mathrm{R} 229 \mathrm{Q}}$ mice could favor the expansion of $\mathrm{T}$ cell clones with inappropriate reactivity toward self-peptide/MHC complexes and development of immunopathology. In addition, because compensatory peripheral $\mathrm{T}$ cell expansion in lymphopenia was previously shown to produce autoimmune disease (26), the reduced thymic output in $R a g 2^{\mathrm{R} 229 \mathrm{Q} / \mathrm{R} 229 \mathrm{Q}}$ mice could predispose animals to autoimmunity. A defective expression of tissue-specific self antigens controlled by AIRE contributes to the pathogenesis of autoimmune manifestations $(27,28)$. Rag2 $2^{\mathrm{R} 229 \mathrm{Q} / \mathrm{R} 229 \mathrm{Q}}$ mice have atrophic thymi and barely detectable Aire expression, suggesting a defect in negative selection of potentially self-reactive T cells $(25,29)$. The defective Aire expression might lead to the severe lymphocyte infiltration in target organs observed in the livers, lungs, and skin of affected mice. In Rag $2^{\mathrm{R} 229 \mathrm{Q} / \mathrm{R} 229 \mathrm{Q}}$ mice, few DP cells were detected and TCR- $\beta$ chains were undetectable by intracellular staining in DN cells (data not shown), implying severe impairment of pre-TCR expression and signaling. Because signaling by the pre-TCR could influence thymic epithelium development (30), we speculate that 

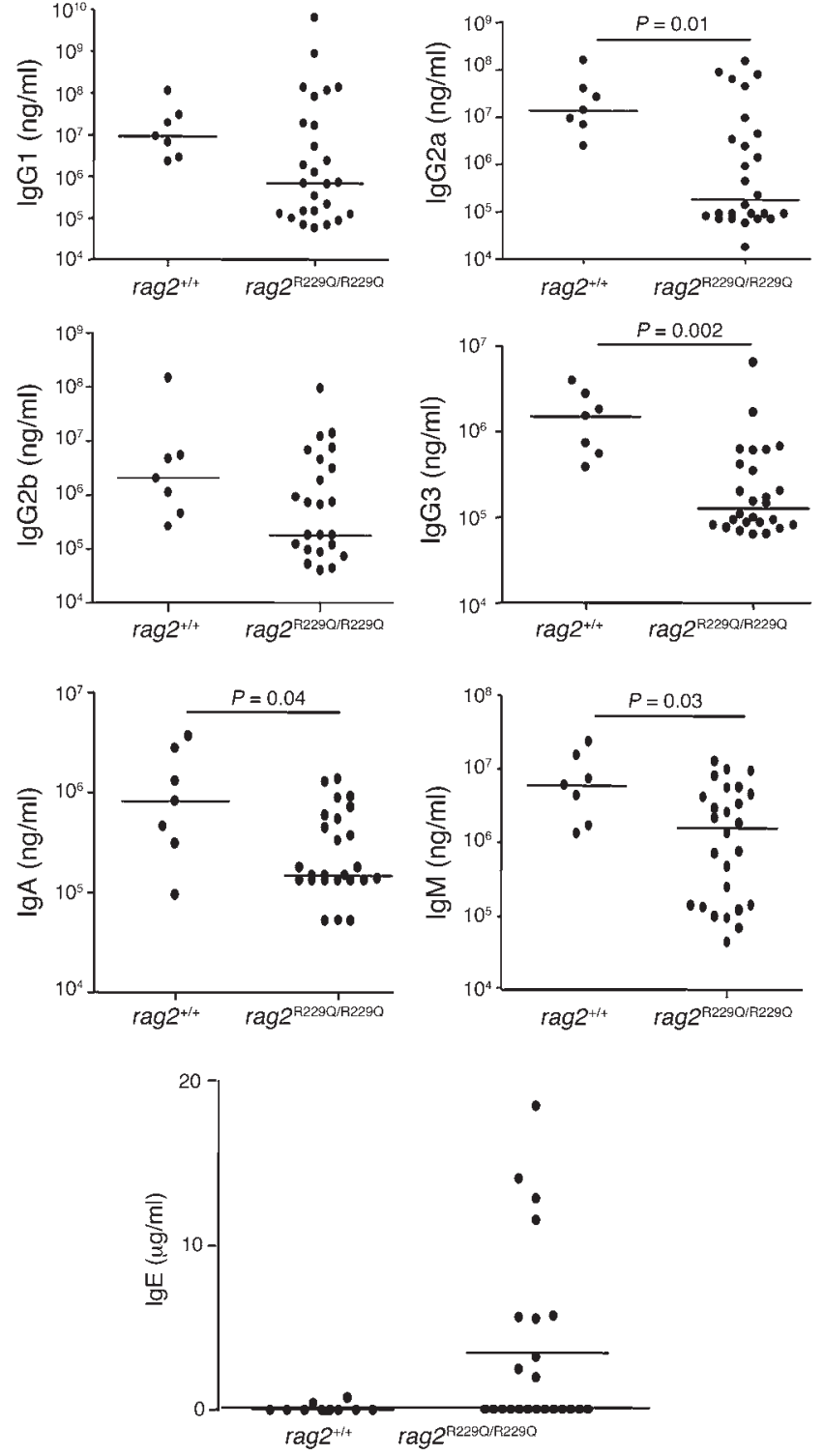

Figure 7

Serum concentration of Igs. Sera from $\operatorname{Rag}^{+/+}$and $R a g 2^{\mathrm{R} 229 Q} / \mathrm{R} 229 \mathrm{Q}$ mice were collected and their $\lg G 1, \lg G 2, \lg G 3$, IgA, and $\lg M$ were evaluated by Bioplex analysis, while ELISA assay was performed to measure IgE production. Bars represent the median for each group. $P$ values were determined by Mann-Whitney test.

inefficient TCR rearrangement and reduced pre-TCR signaling in $\operatorname{Rag} 2^{\mathrm{R} 229 \mathrm{Q} / \mathrm{R} 229 \mathrm{Q}}$ mice would result in impaired medullary expansion and Aire expression. We have also found that the number of nTregs was dramatically reduced in the thymi and peripheral tissues of the $\operatorname{Rag} 2^{\mathrm{R} 229 \mathrm{Q} / \mathrm{R} 229 \mathrm{Q}}$ mice, suggesting that impaired peripheral tolerance may also contribute to the development of autoimmunity in our murine model.

In contrast to the leakiness observed in the T cell compartment, $\mathrm{B}$ cell differentiation was more heavily affected in $\operatorname{Rag}^{\mathrm{R} 229 \mathrm{Q} / \mathrm{R} 229 \mathrm{Q}}$ mice, with a predominant block at the pro-B cell stage and a dearth of mature B lymphocytes both in the bone marrow and in the periphery. These findings largely overlap those reported in patients with OS (31).
The observation that the leakiness of the immunological phenotype of Rag $2^{\mathrm{R} 229 \mathrm{Q} / \mathrm{R} 229 \mathrm{Q}}$ mice was more apparent in $\mathrm{T}$ than in B lymphocytes, while consistent with observations in patients with OS, may reflect stronger pressure for peripheral expansion within the $\mathrm{T}$ lymphocyte lineage.

A remarkable finding of the present study was the variability of the phenotypic manifestations observed in $\operatorname{Rag} 2^{\mathrm{R} 229 \mathrm{Q} / \mathrm{R} 229 \mathrm{Q}}$ mice, with $60 \%$ of mice developing skin and hair abnormalities and $4 \%$ developing severe erythrodermia and weight loss. This variability mimicked that observed in humans and may be due to different factors, including variability in the genetic background.

The analysis of intracellular cytokine production after stimulation with PMA/ionomycin revealed increased production of IL-2, IFN- $\gamma$, and TNF- $\alpha$, indicating Th 1 profile production. These findings are in contrast with observations in OS patients. We speculate that environmental factors and antigen overload could play a role in the induction of increased IL-4 production and thereby favor IgE synthesis in patients with OS. Moreover, genetic background has been shown to influence Th1/Th2 balance and IgE serum levels (32). The Rag2 $2^{\mathrm{R} 229 \mathrm{Q} / \mathrm{R} 229 \mathrm{Q}}$ mice generated in our laboratory carried the hypomorphic Rag2 mutation on a mixed Sv129 $\times \mathrm{C} 57 \mathrm{BL} / 6$ genetic background. In addition, these mice were kept under specific pathogen-free conditions. Therefore, we cannot exclude a possible effect of antigen encounter on the complexity of phenotypic manifestations. Future experiments with pathogen exposure and antigen challenge will help clarify this issue. The hypothesis that infiltration of target organs by oligoclonal $\mathrm{T}$ cells in patients with OS could be a result of defective negative selection of autoreactive $\mathrm{T}$ cell clones can now be explored by crossing Rag $2^{\mathrm{R} 229 \mathrm{Q} / \mathrm{R} 229 \mathrm{Q}}$ mice with TCR transgenic mice, followed by exposure to the specific antigen.

In summary, we have shown that introduction of a homozygous Rag2 R229Q mutation in mice caused disturbed lymphoid development and phenotypic changes that largely recapitulated the spectrum of clinical manifestations associated with hypomorphic $R A G$ mutations seen in humans with OS. Therefore, we propose this mouse model may be a useful tool to gain further insight into the pathophysiology of this complex syndrome.

\section{Methods}

Construction of Rag2-R229Q/GFP targeting vector. QuikChange XL Site-Directed mutagenesis kit (Stratagene) was used to introduce nucleotide changes in the SalI/AseI Rag2 fragment containing the coding region (GenBank accession number AC084753). The first nucleotide exchange was $\mathrm{GC} \rightarrow \mathrm{AG}$ at position 841-842, which led to the R229Q amino acid change. In addition, in order to perform an easier identification of the targeted ES clones, we introduced 2 silent mutations at positions $823(\mathrm{~A} \rightarrow \mathrm{G})$ and $826(\mathrm{~T} \rightarrow \mathrm{A})$, creating a new NheI site. The mutated SalI/AseI fragment was subsequently cloned into the SacI site of the Clontech pEGFP-N1 vector and sequenced in order to verify that the RAG2 GFP fusion gene was in frame (pRAG2-EGFP-N1 construct). This step was performed according to the strategy previously described by Monroe et al. (18). A 750-bp AseI/KpnI fragment containing the 3' UTR of Rag2 was cloned into the NotI site of the pRAG2-EGFP-N1 construct (pRAG-EGFP-UTR-N1 construct). The Rag2 coding region fused to GFP was subsequently cloned into a pPNT vector containing a floxed neo cassette. Finally, a 5' homology fragment of $3.0 \mathrm{~kb}$ (ClaI/SalI) was cloned upstream the mutated Rag2-GFP segment, while a 2.2-kb ClaI/BamHI 3' homology fragment was inserted downstream of the neo cassette.

Generation of Rag $2^{R 229 Q / R 229 Q}$ mice. Animal experiments protocol has been approved by the Ministry of Health and Local authorities (Institutional Ani- 


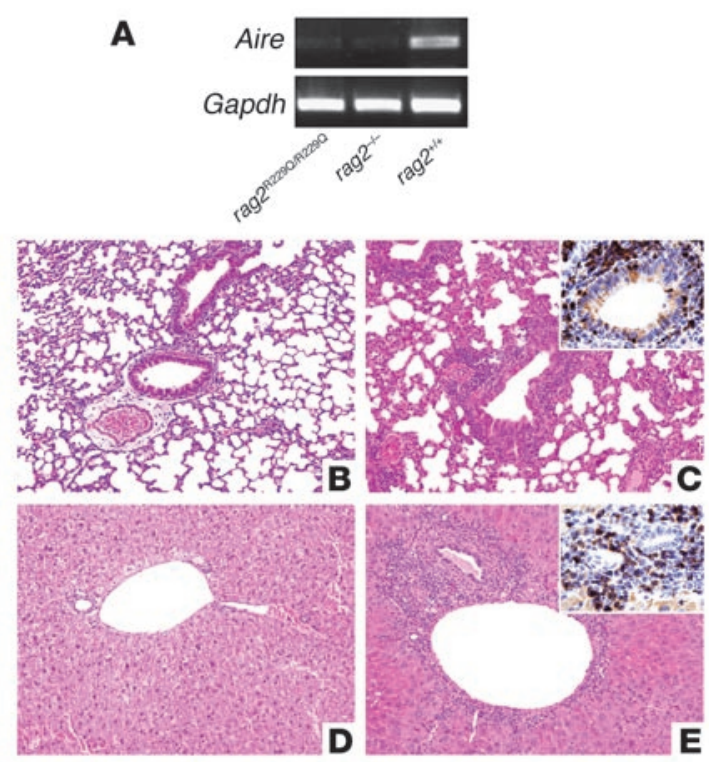

mal Care and Use Committee 5/2005, Milan, Italy). The Rag2 targeting vector was transfected into $129 \mathrm{~Sv}$ ES cells according to standard electroporation procedures using $40 \mu \mathrm{g}$ of linearized NotI plasmid, and ES clones were selected by G418/gancyclovir resistance. Targeted ES clones were screened by PCR, using a $5^{\prime}$ primer located upstream of the targeting vector insertion site and a 3 ' primer downstream of the NheI site, and subsequently sequenced to verify the presence of nucleotide changes. Positive clones were further confirmed by Southern blot analysis using a probe located in the $3^{\prime}$ region (a 520-bp BamHI/EcoRV fragment) on EcoRV-digested genomic DNA. Targeted ES clones were injected in blastocysts, the resulting chimeras were bred with $\mathrm{C} 57 \mathrm{BL} / 6$ mice, and heterozygous animals were identified with the same approach used to identify ES clones. These mice were crossed to CMV-Cre transgenic mice in order to achieve neo cassette excision. Southern blot analysis performed on EcoRV-digested genomic DNA using the previously described probe revealed neo cassette excision: the heterozygous floxed mice showed a wild-type band together with a slightly shorter band as a result of the introduction of an additional (polylinker-derived) EcoRV site during the vector construction. We intercrossed Rag2 $2^{+/ R 229 Q}$ mice to produce homozygous knockin Rag2 $2^{\mathrm{R} 229 \mathrm{Q} / \mathrm{R} 229 \mathrm{Q}}$ mice.

Histology. Mice were sacrificed at different time points after birth, and tissue samples were partially fresh-frozen in cryostat embedding medium (Bio-Optica) and partially fixed in 10\% neutral-buffered formalin for both paraffin embedding and cryoprotection in $30 \%$ sucrose/PBS before freezing into cryostat embedding medium. Sections from both paraffin and frozen blocks were submitted for histological and immunohistochemical evaluation. H\&E staining was used to study basic histopathological features. Frozen sections were air-dried for 18-24 hours, then fixed in acetone and used for immunohistochemistry by an indirect immunoperoxidase technique. The following primary antibodies were applied: rat anti-CD $3 \varepsilon$ (clone CT-CD3; Valter Occhiena), rat anti-CD4 (clone GK1.5; Southern

\section{Figure 9}

Analysis of $n$ Tregs in Rag2R229Q/R229Q mice. (A) Fluorescence-activated cell sorting analysis of thymus and spleen cells stained with CD25 and Foxp3 antibodies electronically gated on CD4 ${ }^{+}$cells. Numbers indicate the percentages of total live cells. (B) Histograms show percentage of CD25 highFoxp3 ${ }^{+}$cells in thymi, spleens, and lymph nodes of $R$ ag2 ${ }^{+/+}$and Rag2 $2^{\mathrm{R} 229 \mathrm{Q} / \mathrm{R} 229 \mathrm{Q}}$ mice. $P$ values were determined by unpaired Student's $t$ test.

\section{Figure 8}

AIRE expression analysis and cellular infiltration in target organs. (A) Amplification of Aire cDNAs obtained from Rag2 ${ }^{+/+}$, Rag2 R229Q/R229Q, and Rag2 $2^{-/-}$thymic mRNAs. As an internal control, Gapdh was used. (B-E) Inflammatory infiltration in the lungs and livers of Rag2 $2^{+/+}$and Rag2R229Q/R229Q mice. Compared with the Rag2+/+ mouse (B), histological analysis of a representative 4-month-old Rag2R229Q/R229Q mouse revealed dense peribronchiolar and perivascular inflammatory infiltration in the lung (C) composed mainly of $\mathrm{CD}^{+}$lymphocytes (C, inset). Similarly, in contrast to the control mouse (D), dense inflammatory infiltration composed of $\mathrm{CD}^{+} \mathrm{T}$ cells was found in liver portal tracts ( $\mathrm{E}$ and inset). Original magnification, $\times 10(B-E) ; \times 40$ (insets).

Biotechnology Associates), rat anti-CD8 (clone CT-CD8a; Valter Occhiena), rat anti-B220 (clone RA3-6B2; Valter Occhiena), and goat anti-CD30 (clone TNFRSF8; R\&D Systems). Immunostains on paraffin sections for CD30 and CD3 were performed upon antigen retrieval with microwave treatment in $1.0 \mathrm{mM}$ EDTA buffer, $\mathrm{pH}$ 8.0, for 15 minutes. Primary antibodies were applied for 2 hours and followed by 30 minutes' incubation in buffer containing the biotinylated specific secondary antibodies (Vector Laboratories). Immunolabeling was then performed by incubation for

20 minutes with streptavidin-peroxidase amplification system (BioGenex) and revealed using 3-amino-9-ethylcarbazole (Lab Vision). Slides were counterstained with hematoxylin. Images were acquired with an Olympus DP70 digital camera mounted on an Olympus BX60 microscope, using AnalySIS imaging software (version 3.2; Olympus).

Lymphocyte proliferation and intracellular cytokine staining. $\mathrm{CD} 90^{+} \mathrm{T}$ cells were purified from splenocytes of Rag2 ${ }^{\mathrm{R} 229 \mathrm{Q} / \mathrm{R} 229 \mathrm{Q}}$ mice using anti-CD90 MACS microbeads (Miltenyi Biotec); resuspended in RPMI 1640 containing $10 \%$ heat-inactivated FCS, $2 \mathrm{mM}$ glutamine and penicillin/streptomycin $(100 \mathrm{IU} / \mathrm{ml})$, and $10 \mu \mathrm{M} 2$-mercaptoethanol; and placed in flat-bottomed 96-well plates in the presence of surface-bound anti-mouse CD3 $\mathrm{mAb}$ $(0.2,2$, and $20 \mu \mathrm{g} / \mathrm{ml}$ ) alone or combined with $100 \mathrm{IU} / \mathrm{ml} \mathrm{IL-2} \mathrm{(Proleukin}$ [aldesleukin]; Chiron) and $2 \mu \mathrm{g} / \mathrm{ml}$ anti-CD28. After 72 hours, cells were pulsed for $14-16$ hours with $0.037 \mathrm{MBq}(1 \mu \mathrm{Ci})$ per well of $\left[{ }^{3} \mathrm{H}\right]$-thymidine (Amersham Pharmacia Biotech). Cells were then harvested, and proliferation (in cpm) was measured in a scintillation counter. For intracellular cytokine staining, $1 \times 10^{6}$ cells obtained from lymph nodes were stimulated for 2 hours with $1 \mathrm{mM}$ ionomycin and $10^{-6} \mathrm{M}$ PMA. After addition of $5 \mu \mathrm{g} / \mathrm{ml}$ brefeldin A for 2 hours, cells were stained with FITC-conjugated CD8 and PerCP-conjugated CD4 antibodies. Cells were fixed in $2 \%$ formaldehyde and, after washing in permeabilization buffer (PBS containing $2 \%$ FCS and $0.5 \%$ saponin), were stained with allophycocyanin-conjugated (APC-conjugated) anti-IFN- $\gamma$, PE-conjugated anti-IL-4, APC-conjugated anti-TNF- $\alpha$, and APC-conjugated anti-IL-2 antibodies.

Fluorescence-activated cell sorting analysis and antibodies. Single cell suspensions from thymi, bone marrow, spleens, and lymph nodes were prepared and stained with specific fluorescent-conjugated antibodies. Thymocytes were incubated with the following antibodies: APC- or PerCP-conjugated anti-CD4, PE- or CyChrome-conjugated anti-CD8, FITC-conjugated antiCD44, PE-conjugated anti-CD25, FITC-conjugated anti-CD69, PE-conjugated anti-TCR- $\gamma$, and FITC-conjugated anti-TCR- $\beta$. Bone marrow, spleen, and lymph node cells were stained with PE-conjugated anti-B220, biotin-conjugated anti-CD43, PE-conjugated anti-IgM, FITC-conjugated anti-IgD, FITC-conjugated anti-CD21, and PE-conjugated anti-CD23. Samples stained with byotin-conjugated antibodies underwent an additional incubation with CyChrome-conjugated streptavidin. PE-conjugated anti-CD1d tetramer antibodies were kindly provided by C. Terhorst (Harvard Medical School, Boston, Massachusetts, USA). The staining with anti-Foxp3 mAbs (FJK-16s; eBioscience) was performed following the manufacturer's instructions. All the antibodies used were from BD. At least 100,000 live cells were acquired on a FACSCalibur system (BD) and analyzed with FLOWJO software (version 4.5.4; Treestar Inc.).

Serum Ig quantification and specific antibody production. Levels of IgG1, IgG2a, IgG2b, IgG3, IgA, and IgM were measured in sera collected from Rag2 2229 /R229Q mice by multiplex assay kit (Beadlyte Mouse Immunoglobulin Isotyping Kit; Upstate). Samples were prepared according to the manufacturer's instructions. The assay was run using Bio-Plex reader (BioRad). Levels of IgE were determined by ELISA assay (BD Biosciences).

To verify antigen-specific production, anesthetized mice were injected subcutaneously into footpads with $100 \mu \mathrm{g}$ OVA (grade V; Sigma-Aldrich) mixed at a 1:1 ratio with CFA (Sigma-Aldrich). OVA-specific IgM, IgG1, IgG2a, and IgG2b levels were assessed by ELISA on serum obtained 7 days following boost, performed one month after the first immunization.

$R N A$ extraction and RT-PCR. Total RNA was prepared from the thymus using SV-total RNA isolation kit (Promega) followed by DNAse digestion in order to eliminate any residual DNA. Reverse transcription was performed with SuperScript II according to the manufacturer's directions (Invitrogen). An aliquot (1 $\mu \mathrm{l}$ ) of cDNA was used for the PCR reaction (30 cycles; annealing temperature, $58^{\circ} \mathrm{C}$ ) in PerkinElmer Gene Amp9700 System to assess the expression of Aire with the following primers: forward, 5'-TGCATAGCATCCTGGACGGCTTCC-3'; reverse, 5'-CCTGGGCTGGAGACGCTCTTTGAG-3'. As an internal control, Gapdh transcript was amplified with the following oligos: forward, $5^{\prime}$-TGTCAGCAATGCATCCTGCA-3'; reverse, 5'-TGGATGCAGGGATGATGTTC-3'.

$T C R V \beta$ quantitative immunoscope analysis. cDNAs were obtained from $\mathrm{CD} 90^{+}$cells isolated from thymus and spleen using positive selection (Miltenyi Biotec). TCRV $\beta$ repertoire analysis was performed as previously described (33). Briefly, cDNA was amplified with each of the 24 TCRV $\beta$ family member-specific primers together with a TCRC $\beta$ primer and a TaqMan Minor Groove Binder (MGB) Probe (Applied Biosystems) for TCRC $\beta$. Real-time quantitative PCR was carried out on an ABI 7300 system (Applied Biosystems). PCR products were then subjected to runoff reactions using a nested fluorescent primer specific for the TCRC $\beta$ segment. The fluorescent products were separated and analyzed on a 373A sequencer (Applied Biosystems). The size and intensity of each band were analyzed by the quantitative Immunoscope approach $(33,34)$. The Gaussian distribution of the different CDR3 lengths was characteristic of normal TCRV $\beta$ repertoire.

Statistics. For comparison between groups, an unpaired 2-tailed Student's $t$ test was used. Mann-Whitney test (nonparametric analysis) was used to evaluate the significance of Ig differences. A $P$ value less than 0.05 was considered significant.

\section{Acknowledgments}

We are grateful to the laboratory of Michel Nussenzweig, which kindly provided the BAC-containing Rag2 genomic region. We thank Enrica Mira Cato (Institute for Research in Biomedicine) for technical assistance. This work was supported by GATA 0203 AFM/Telethon (to A. Villa and L.D. Notarangelo); Stellar project (to P. Vezzoni), from Fondazione Cariplo (Nobel project to A. Villa, P. Vezzoni, and L.D. Notarangelo), and PRIN 2004 (to F. Facchetti). A. Casati is supported by Fondazione Stella Major.

Received for publication November 13, 2006, and accepted in revised form March 6, 2007.

Address correspondence to: Anna Villa, Istituto di Tecnologie Biomediche, CNR Via Fratelli Cervi 93, Segrate, Milan 20090, Italy. Phone: 0039-02-26422636; Fax: 0039-02-26422660; E-mail: anna.villa@itb.cnr.it.
1. Honig, M., and Schwarz, K. 2006. Omenn syndrome: a lack of tolerance on the background of deficient lymphocyte development and maturation. Curr. Opin. Rheumatol. 18:383-388.

2. Notarangelo, L.D., Gambineri, E., and Badolato, R. 2006. Immunodeficiencies with autoimmune consequences. Adv. Immunol. 89:321-370.

3. Omenn, G.S. 1965. Familial reticuloendotheliosis with eosinophilia. N. Engl. J. Med. 273:427-432.

4. Santagata, S., Villa, A., Sobacchi, C., Cortes, P., and Vezzoni, P. 2000. The genetic and biochemical basis of Omenn syndrome. Immunol. Rev. 178:64-74.
5. Mazzolari, E., et al. 2005. Hematopoietic stem cell transplantation in Omenn syndrome: a single-center experience. Bone Marrow Transplant. 36:107-114.

6. Sobacchi, C., Marrella, V., Rucci, F., Vezzoni, P., and Villa, A. 2006. RAG-dependent primary immunodeficiencies. Hum. Mutat. 27:1174-1184.

7. Harville, T.O., Adams, D.M., Howard, T.A., and Ware, R.E. 1997. Oligoclonal expansion of $\mathrm{CD}_{45 \mathrm{RO}^{+}} \mathrm{T}$ lymphocytes in Omenn syndrome. J. Clin. Immunol. 17:322-332.

8. Signorini, S., et al. 1999. Intrathymic restriction and peripheral expansion of the T-cell repertoire in
Omenn syndrome. Blood. 94:3468-3478.

9. Villa, A., et al. 1998. Partial V(D)J recombination activity leads to Omenn syndrome. Cell. 93:885-896.

10. Corneo, B., et al. 2001. Identical mutations in RAG1 or RAG2 genes leading to defective $V(D) J$ recombinase activity can cause either T-B-severe combined immune deficiency or Omenn syndrome. Blood. 97:2772-2776.

11. Villa, A., et al. 2001. V(D)J recombination defects in lymphocytes due to RAG mutations: severe immunodeficiency with a spectrum of clinical presentations. Blood. 97:81-88. 
12. Giliani, S., et al. 2006. Omenn syndrome in an infant with IL7RA gene mutation. J. Pediatr. 148:272-274.

13. Roifman, C.M., Gu, Y., and Cohen, A. 2006. Mutations in the RNA component of RNase mitochondrial RNA processing might cause Omenn syndrome. J. Allergy Clin. Immunol. 117:897-903.

14. Ege, M., et al. 2005. Omenn syndrome due to ARTEMIS mutations. Blood. 105:4179-4186.

15. Schwarz, K., et al. 1996. Rag mutations in human B cell negative SCID. Science. 274:97-99.

16. Farr, A., Nelson, A., Truex, J., and Hosier, S.J. 1991. Epithelial heterogeneity in the murine thymus: a cell surface glycoprotein expressed by subcapsular and medullary epithelium. J. Histochem. Cytochem. 39:645-653.

17. Wilson, A., Held, W., and MacDonald, H.R. 1994 Two waves of recombinase gene expression in developing thymocytes. J. Exp. Med. 179:1355-1360.

18. Monroe, R.J., et al. 1999. RAG2:GFP knockin mice reveal novel aspects of RAG2 expression in primary and peripheral lymphoid tissues. Immunity. 11:201-212.

19. Shinkai, Y., et al. 1992. RAG-2-deficient mice lack mature lymphocytes owing to inability to initiate V(D)J rearrangement. Cell. 68:855-867.

20. Thevenin, C., Nutt, S.L., and Busslinger, M. 1998. Early function of Pax5 (BSAP) before the pre-B cell receptor stage of B lymphopoiesis. J. Exp. Med.
188:735-744

21. Oliver, A.M., Martin, F., and Kearney, J.F. 1999. $\operatorname{Ig} M^{\text {high }} \mathrm{CD} 21^{\text {high }}$ lymphocytes enriched in the splenic marginal zone generate effector cells more rapidly than the bulk of follicular B cells. J. Immunol. 162:7198-7207.

22. Sakaguchi, S., et al. 2006. Foxp $3^{+} \mathrm{CD} 25^{+} \mathrm{CD} 4^{+}$natural regulatory $\mathrm{T}$ cells in dominant self-tolerance and autoimmune disease. Immunol. Rev. 212:8-27.

23. de Villartay, J.P., et al. 2005. A novel immunodeficiency associated with hypomorphic RAG1 mutations and CMV infection. J. Clin. Invest. 115:3291-3299. doi:10.1172/JCI25178.

24. Ehl, S., et al. 2005. A variant of SCID with specific immune responses and predominance of $\gamma \delta \mathrm{T}$ cells. J. Clin. Invest. 115:3140-3148. doi:10.1172/ JCI25221.

25. Cavadini, P., et al. 2005. AIRE deficiency in thymus of 2 patients with Omenn syndrome. J. Clin. Invest. 115:728-732. doi:10.1172/JCI200523087.

26. King, C., Ilic, A., Koelsch, K., and Sarvetnick, N. 2004. Homeostatic expansion of $\mathrm{T}$ cells during immune insufficiency generates autoimmunity. Cell. 16:265-277.

27. Derbinski, J., Schulte, A., Kyewsk, B., and Klein, L. 2001. Promiscuous gene expression in medullary thymic epithelial cells mirrors the peripheral self. Nat. Immunol. 2:1032-1039.

28. Anderson, M.S., et al. 2005. The cellular mecha- nism of Aire control of $\mathrm{T}$ cell tolerance. Immunity. 23:227-239.

29. Liston, A., Lesage, S., Wilson, J., Peltonen, L., and Goodnow, C.C. 2003. Aire regulates negative selection of organ-specific T cells. Nat. Immunol. 4:350-354.

30. Porcellini, S., Panigada, M., and Grassi, F. 1999. Molecular and cellular aspects of induced thymus development in recombinase-deficient mice. Eur. J. Immunol. 29:2476-2483.

31. Noordzij, J.G., et al. 2002. The immunophenotypic and immunogenotypic B-cell differentiation arrest in bone marrow of RAG-deficient SCID patients corresponds to residual recombination activities of mutated RAG proteins. Blood. 100:2145-2152.

32. Hosken, N.A., Shibuya, K., Heath, A.W., Murphy, K.M., and O'Garra, A. 1995. The effect of antigen dose on CD4+ T helper cell phenotype development in a $\mathrm{T}$ cell receptor-alpha beta-transgenic model. J. Exp. Med. 182:1579-1584.

33. Lim, A., et al. 2002. Combination of MHC-peptide multimer-based $\mathrm{T}$ cell sorting with the Immunoscope permits sensitive ex vivo quantitation and follow-up of human $\mathrm{CD}^{+} \mathrm{T}$ cell immune responses. J. Immunol. Methods. 261:177-194.

34. Pannetier, C., et al. 1993. The sizes of the CDR3 hypervariable regions of the murine T-cell receptor beta chains vary as a function of the recombined germ-line segments. Proc. Natl. Acad. Sci. U. S. A. 90:4319-4323. 